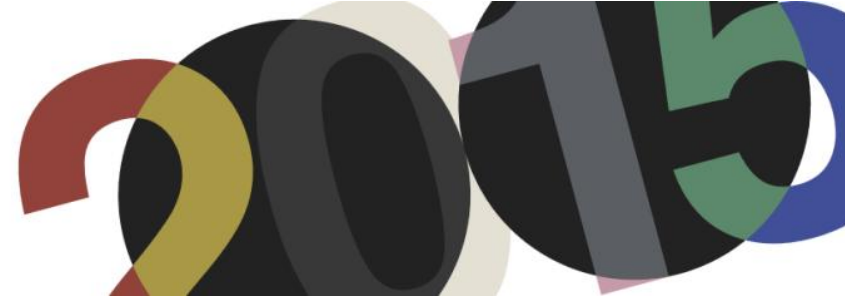

DOI: http://dx.doi.org/10.4995/LC2015.2015.527

\title{
La mediterraneidad en la obra de Le Corbusier. La bóveda catalana lecorbuseriana: Influencias y evolución
}

\author{
E. López García \\ Seconda Università degli Studi di Napoli. Dipartimento di architettura e disegno industriale Luigi Vanvitelli
}

\begin{abstract}
Resumen: Le Corbusier durante gran parte de su vida busca volver la vista hacia las tradiciones mediterráneas. Con el fin de desvelar la arquitectura y el paisaje españoles, realiza un gran número de viajes en tren y coche a lo largo de su territorio y será durante su visita a Barcelona en 1928 cuando nace su interés por la técnica de la bóveda catalana. Es una época de su carrera en la que empieza a interesarse por métodos de construcción y materiales tradicionales. Para el arquitecto la bóveda catalana es un sistema con grandes posibilidades formales y una gran flexibilidad frente a su sencillez de medios. Le Corbusier muestra la influencia de sus viajes por el Mediterráneo, en especial de su viaje a Barcelona, y de su relación con varios arquitectos españoles en una gran cantidad de obras residenciales realizadas entre los años 20 y 50. Consiguió definir la expresividad del proyecto a través de la repetición de un único elemento arquitectónico, el sistema abovedado sobre una retícula, y de la utilización de diversos materiales como el ladrillo, vidrio y hormigón. Tras años de estudios de estos elementos el arquitecto adapta la bóveda catalana a las innovaciones estructurales del hormigón armado, demostrando una gran autonomía formal y temporal respecto al resto de sus proyectos y consiguiendo aunar tradición y modernidad en una única obra.
\end{abstract}

Abstract: Throughout his life Le Corbusier was inspired by Mediterranean traditions. In order to discover Spanish architecture and landscape, he went on numerous of car and train trips throughout its territory. During his visit to Barcelona in 1928 he discovered the craftsmanship of thin-tile Catalan vaults. This was a period in his career in which he began to be interested in traditional building methods and materials. Le Corbusier looked at Catalan vaults as a very flexible formal system versus its simplicity of means. He showed the influence of his travels around the Mediterranean, particularly when he travelled to Barcelona and his relationship with many Spanish architects, in a large number of residential projects built between the 20s and the 50s. He managed to define the project expressivity through the repetition of an unique architectural element, the vault on a grid system, and the use of different materials such as brick, glass and concrete. After several years studying these elements he was able to adapt the Catalan vault system to innovative reinforced concrete structural solutions, showing a great formal and temporary autonomy compared to the rest of his projects while combining tradition and modernity in a unique work..

Palabras clave: Mediterráneo; viajes; bóveda catalana; tradición; modernida.

Keywords: Mediterranean; trips; Catalan vault; tradition; modernity.

\section{Viajes de le Corbusier por españa}

“A lo largo de estos años me convertí en un hombre de todas partes, viajé a través de los continentes. No tengo más que una atadura profunda: el Mediterráneo. Soy fuertemente mediterráneo...Mediterráneo, reino de las formas en la luz. La luz en el espacio....En todo me siento mediterráneo. Mi resorte, mis fuentes, hay que encontrarlas en el mar que nunca dejé de amar. " Le Corbusier ${ }^{1}$

\footnotetext{
${ }^{1}$ Le Corbusier. Discurso "Air, son, lumière”. Pronunciado en Atenas el 3 de agosto de 1933 con motivo del IV CIAM.
} Atenas, 1933. 
Le Corbusier se definía constantemente como un amante de los paisajes y de la cultura mediterránea. Se encontraba en una constante búsqueda de la perspectiva de la mediterraneidad y quizás fue este interés lo que le llevó a visitar España en numerosas ocasiones. Definió España como un país ardiente y místico y dedicó varios de sus viajes en tren y coche a analizar gran parte de sus lugares, desde las principales ciudades hasta los pueblos más remotos de Castilla. A través de sus viajes asimilaba los secretos de la intervención humana en el territorio y los plasmaba en sus cuadernos. Así confirmó que ninguna forma de representación gráfica podría sustituir una experiencia espacial. Inició su experiencia en España en 1928 recorriendo Castilla en tren de camino a Madrid, visitó también Segovia, Toledo y El Escorial. En las entrevistas llevadas a cabo en España insistió en las raíces mediterráneas de su obra y en la superioridad del mundo latino frente a los pueblos del norte. Le Corbusier siempre exaltó la claridad y precisión plástica del sur².

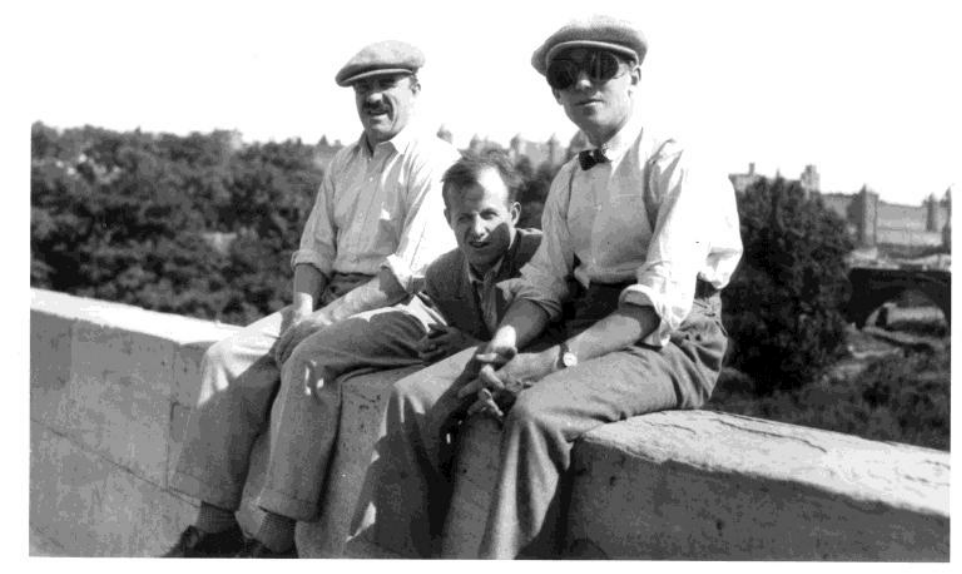

1. Fernand Léger, Pierre Jeanneret et Le Corbusier en España, 1930. @ FLC-ADAGP.

Posteriormente, en 1930 realiza otro viaje por España, esta vez en coche, acompañado por Fernand Leger, Pierre Jeanneret y Albert Jeanneret. Recorrieron la costa del Mediterráneo y el sur de España, volviendo a Madrid y regresando a Francia a través de San Sebastián. A diferencia de su anterior viaje, en este último quedó impresionado por los paisajes y las infraestructuras de la Península. Las arquitecturas vernáculas españolas que observaba a gran velocidad desde las carreteras recorridas le servirían como inspiración para futuros proyectos. Impresionado por la vasta y tranquila naturaleza del lugar Le Corbusier comentó: "Los españoles, son un pueblo que tienen la fortuna hoy de ser el único en el mundo de vivir en un estado de serenidad sublime"2 Como podemos observar el Mediterráneo siempre estuvo muy presente en su obra y gracias a ello según autores como Josep Farran i Mayoral Le Corbusier ha conseguido encaminar a la arquitectura por el buen camino de las grandes tradiciones mediterráneas.

\section{Aproximación a la técnica de la bóveda catalana durante su viaje a Barcelona}

Serán sus viajes a Barcelona los que harán despertar en Le Corbusier el interés por la técnica constructiva de la bóveda catalana. Durante su estancia en Madrid en 1928 fue invitado por su gran discípulo Josep Lluís Sert para acudir a Barcelona. Lo curioso es que el recibimiento en ambas ciudades fue radicalmente distinto, explica

\footnotetext{
${ }^{2}$ Lahuerta, Juan José. Le Corbusier e la Spagna, con la riproduzione dei carnets Barcelone e C10 di Le Corbusier. Milano: Mondadori Electa, 2006.
} 
Salvador Guerrero, comisario del ciclo de la Residencia de estudiantes de Madrid: "En Madrid, los intelectuales, como Ortega y Gasset, le reciben con gran interés; sin embargo, los arquitectos lo hicieron con cierta tibieza, en especial Luis Lacasa, que criticaba su racionalismo formalista y del que decía que era un periodista y charlatán. En cambio, en Barcelona contaba con un peso indiscutible”’3.

Durante esta visita a Barcelona, invitado para pronunciar una conferencia, conoce las obras de Gaudí y da importancia a algunas soluciones constructivas de origen popular, las Escuelas para los hijos de los trabajadores de la Sagrada Familia. Este interés lo demuestra en su Carnet C11 al dibujar las cubiertas onduladas de las escuelas junto a la bóveda catalana acompañados de una gran cantidad de anotaciones técnicas entre ellas medidas y características del sistema constructivo. Le sorprende el ingenio constructivo de la cubierta pues resuelve la forma y estructura del edificio con una lámina fina y delgada ${ }^{4}$. Para él se trata de un sistema con grandes posibilidades formales y una gran flexibilidad, frente a la gran sencillez de medios. Lo que le atrae de Gaudí es que es un hombre de oficio, un constructor con una gran habilidad técnica. Sin embargo, no se interesa tanto por la obra de Gaudí en particular sino por la construcción y formalización de la bóveda catalana. Después de este viaje a Barcelona Le Corbusier recurrirá constantemente a arquitectos catalanes para comprender la técnica de este sistema.

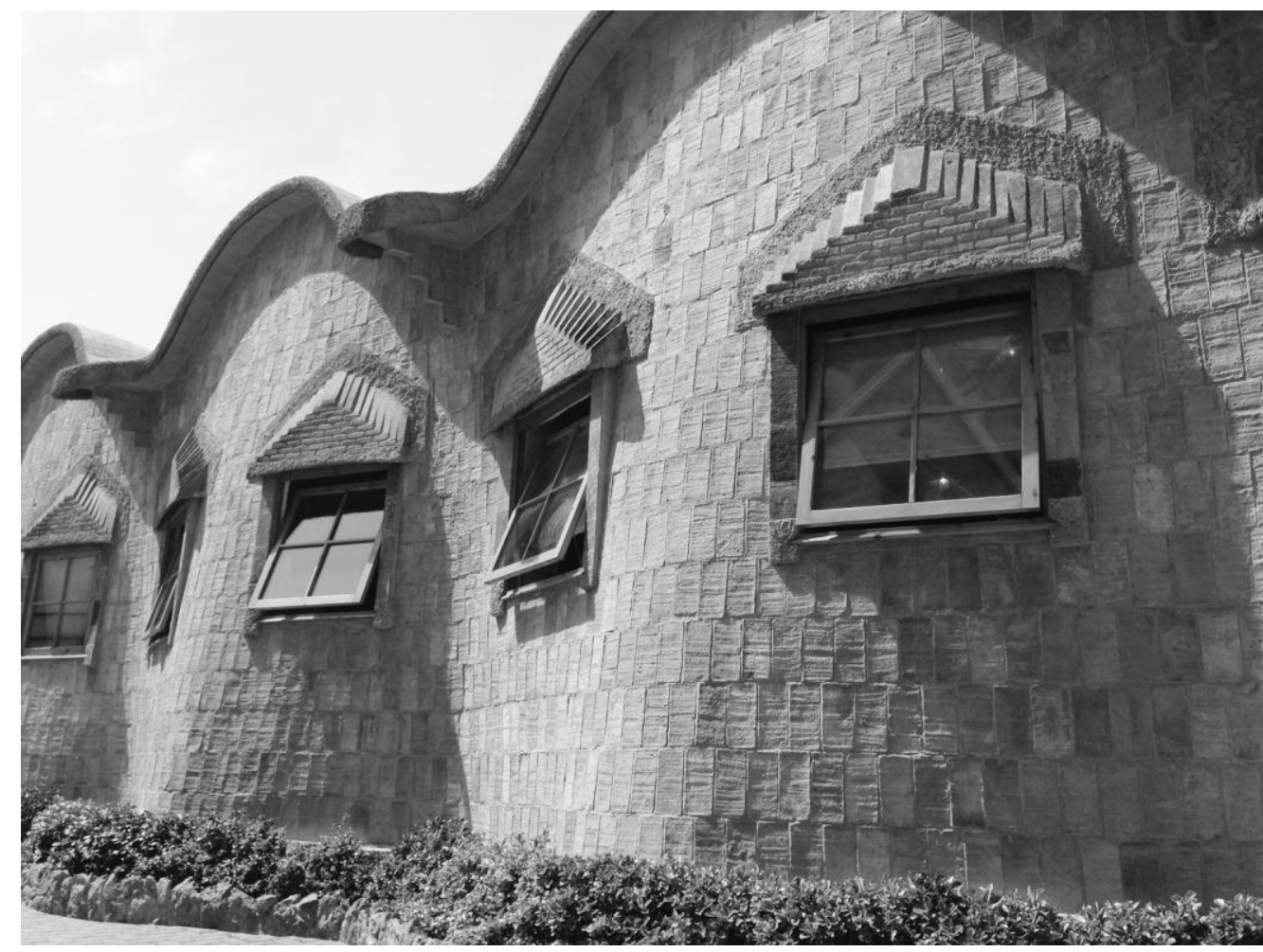

2. Fotografía exterior de las escuelas de la Sagrada Familia. Fuente: Producción propia (Esmeralda López García)

\footnotetext{
${ }^{3}$ Diaz de Tuesta, M.José. Aquel Madrid de Le Corbusier. La Residencia de estudiantes recuerda la estancia de los genios de la arquitectura. Madrid: El País, 2009.

${ }^{4}$ Huerta, Santiago. Las bóvedas de Guastavino en América: libro publicado con ocasión de la exposición: Guastavino Co. (1885-1962) Madrid: Instituto Juan Herrera, 2001.
} 
En los años 20 y 30 se empieza a abismar en el arquitecto un pequeño alejamiento de las posiciones dogmáticas del purismo. Se trata del inicio de una fase de transición en su carrera en la que las técnicas constructivas tradicionales toman cada vez más fuerza en su obra, situándose su viaje a Barcelona en el momento central de esta transición. Le Corbusier poco a poco se aleja de las vanguardias de los años veinte ajenas a la tradición, dirigiendo su obra hacia soluciones basadas en las culturas locales e invitando a los profesionales catalanes a observar la obra de Gaudí y de su entorno más tradicional. Nos encontramos ante una época de su carrera caracterizada por una cierta incertidumbre en la búsqueda de una nueva línea de diseño, en la que combina la estética moderna con la utilización de materiales tradicionales.

\section{Presencia de la bóveda catalana en el movimiento moderno español y relación con Le Corbusier}

La bóveda tabicada tuvo una gran importancia en el movimiento moderno español tanto en Madrid como en Barcelona siendo este elemento el punto de partida de una búsqueda hacia una arquitectura verdadera. Este sistema constructivo convive con las nuevas técnicas empleadas en los años 20 y 30 y se convierte en un elemento capaz de aunar sencillez, tradición y economía de medios. Gracias a estas características el movimiento moderno asume su uso como propio, siendo muy utilizada en viviendas y pequeñas escuelas e irá siempre ligada al concepto de repetición. Además, tuvo mucho auge durante la posguerra española debido a la escasez de materiales del momento histórico y a la situación política del país que desconfiaba de la arquitectura moderna representada por los grupos GATEPAC y GATCPAC. Aun así y a diferencia de las circunstancias de uso iniciales, la bóveda catalana tuvo más transcendencia en los planteamientos radicales del movimiento moderno que en otros arquitectos opuestos a esta postura.

Fue quizás esta aproximación de los arquitectos de la Península a la tradición constructiva lo que generó que Le Corbusier estuviera en continuo contacto con miembros del grupo GATCPAC, Grup d'Arquitectes $i$ Tècnics Catalans per al Progrés de l'Arquitectura Contemporània, sobre todo con Josep Lluís Sert, Josep Torres Clavé y Antoni Bonet i Castellana. Estos arquitectos edificaron proyectos que utilizaban la bóveda catalana en los años treinta. Los dos primeros, aunque autoproclamados modernos y revolucionarios, utilizaron este método en las casas de vacaciones en Garraf (Barcelona, 1934-1935), y Sert lo volverá a emplear en el plan de Chimbote presentado en Bérgamo en $1949^{5}$.

"La buena arquitectura no se ha hecho nunca por fórmula ni siguiendo al pie de la letra una doctrina: sería demasiado sencillo... Podemos, para obtener esto, aprovechar todos los medios que tenemos a mano, desde los más tradicionales a los más modernos; desde la piedra al ladrillo, el hormigón armado, el acero y el cristal, siempre que estén controlados por un espíritu de orden, claridad y respeto a las construcciones milenarias, osatura espiritual de todas las grandes creaciones arquitectónicas ” Josep Lluís Sert ${ }^{6}$

\footnotetext{
${ }^{5}$ Grijalba bengoetxea, Alberto. Cabrero. La arquitectura de Francisco cabrero. Valladolid: Universidad de Valladolid, 2000.

${ }^{6}$ Sert, Josep Luis. ¿Qué orientación debe darse a la arquitectura contemporánea en Cataluña? En revista del GATEPAC. Barcelona 1934, AC nº16 pp. 43-44.
} 
Le Corbusier mantiene una estrecha relación con Sert, con quien reflexiona sobre el sistema de la bóveda tabicada. Éste le habla del maestro catalán especializado en este sistema Doménech Escorsa y a partir de ese momento se convertirá en un punto de referencia constante para Le Corbusier. Con él mantendrá un contacto frecuente para obtener información sobre cómo utilizar este elemento constructivo.

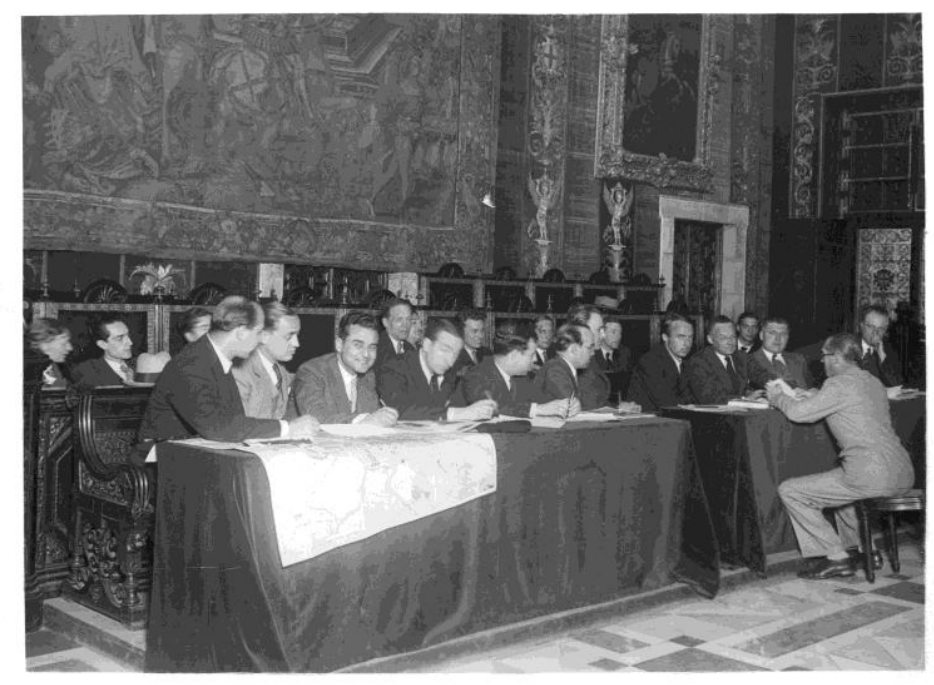

3. Le Corbusier en la reunión del CIRPAC (Comité Internacional para la Resolución de los Problemas de la Arquitectura Contemporánea), Barcelona 1932. Fotógrafo: Sagarra y Torrents. ( FLC-ADAGP.

Otra de las figuras claves en el uso y estudio de la bóveda catalana en España fue Antoni Bonet, colaborador de Sert y de Le Corbusier. Realizará varios proyectos con este sistema como la casa La Ricarda (El Prat de Llobregat, Barcelona, 1963), la casa Martínez (Buenos Aires, 1942) y la Casa Belingheri (Punta Ballena, 1945) Precisamente Bonet colaboró con Le Corbusier en los años 50 durante la evolución del proyecto para la casa Jaoul, realizando algunos croquis de soluciones abovedadas onduladas. Las trayectorias profesionales de Le Corbusier y Bonet, tras abandonar éste último el estudio, estuvieron unidas por dos obras: la Maison de weekend Jaoul y La Ricarda. Además ambos desarrollaron una línea de investigación paralela en torno al tratamiento de los materiales tradicionales y al estudio de la técnica constructiva de la bóveda catalana.

\section{Adaptación del sistema tradicional: Tradición y modernidad}

El interés de Le Corbusier por el método de construir tradicional fue una constante de estudio en su actividad profesional. En particular, ve grandes posibilidades formales en la bóveda catalana. Una de sus líneas de uso en la obra del arquitecto es su aplicación como elemento generador del edificio, pues repitiéndola en secuencia es capaz de definir la forma del complejo y a su vez resolver estructuralmente el proyecto. Recurrirá a esta técnica constructiva de manera recurrente desde su viaje a Barcelona en 1928 hasta inicios de los años 60 ${ }^{7}$. Las principales preocupaciones de Le Corbusier en este periodo eran por un lado la búsqueda de un contraste en los materiales utilizados, desvinculándose de esta manera de las vanguardias del momento, y por otro, encontrar un único elemento formal que fuera capaz de generar el proyecto.

\footnotetext{
${ }^{7}$ Huerta, Santiago. Las bóvedas de Guastavino en América: libro publicado con ocasión de la exposición: Guastavino Co. (1885-1962) Madrid: Instituto Juan Herrera, 2001.
} 
Después de su interés inicial por los sistemas tradicionales será tras su viaje a la India en febrero de 1951 cuando se reaviva en Le Corbusier el interés por la utilización de sistemas constructivos tradicionales. En ese mismo año, durante el congreso internacional de arquitectura moderna CIAM VIII en Hoddesdon, realizó un croquis de una bóveda catalana que incluía información constructiva, de ejecución, dimensiones y materiales aportada por Josep Lluís Sert y Domènec Escorsa. Este croquis lo realiza el 9 de julio de 1951, poco antes de dibujar la sección para la casa Jaoul.

El interés de Le Corbusier por la utilización de la bóveda catalana evoluciona a lo largo de su carrera. Inicialmente era una respuesta formal-tipológica que respondía además a un elemento usado en el Mediterráneo, pero después se convertirá en una solución alternativa a la técnica del hormigón armado. El arquitecto hace numerosas referencias en su obra a la arquitectura vernácula mediterránea y manifiesta una gran preocupación por la bóveda, el muro y los materiales tradicionales.

\section{Uso de la bóveda catalana en la obra de Le Corbusier}

Le Corbusier estudia dos soluciones para reinterpretar el sistema de la bóveda catalana: el tradicional de tres estratos superpuestos y el de dos estratos, realizados con materiales diferentes. Es esta diferencia el principal condicionante que dará como resultado la cubierta tabicada propuesta por Le Corbusier. Se trata de una solución intermedia entre el sistema en hormigón utilizado por los constructores romanos y el sistema tradicional.

En las bóvedas de las obras de Le Corbusier la primera hilada no puede ser considerada completamente colaboradora con la segunda, pues no se lleva a cabo la regla del desfase relativo entre las juntas de ambas capas. El relleno de hormigón aligerado en el trasdós modifica el funcionamiento estructural de la bóveda y es la sección resistente la que comprende la zona del refuerzo. En los años 50 ya integra el sistema tradicional artesanal con las posibilidades estructurales del hormigón armado $^{8}$. El esquema estático de esta solución abovedada equivale al de un arco de hormigón con un tirante que contrarresta el empuje horizontal. De esta manera el arquitecto elimina el valor constructivo de esta técnica conservando únicamente su expresión formal y reelaborando así el sistema. Posteriormente se ha confirmado con las propias notas de Le Corbusier que él consideraba la estructura de ladrillo como encofrado perdido, reduciendo así su capacidad resistente.

\section{La bóveda catalana en los proyectos de Le Corbusier}

\subsection{Proyectos iniciales}

Le Corbusier propone los primeros modelos abovedados en el proyecto no construido de la casa Monol (1919) y la villa Paul Poiret en Sans Lieu (1916) En estas obras sigue el ejemplo de los almacenes Wallut, realizados por Auguste Perret en Casablanca entre 1914 y 1916, y a los cuales hace referencia en su libro 'Une maison-Un palais', en el que trabajaba durante su viaje a España. En la casa Monol se produce una transición desde una forma unitaria de los primeros bocetos hasta un conjunto de unidades volumétricas individuales resueltas mediante la combinación de varios prismas coronados por bóvedas tabicadas. En este caso la cubierta abovedada es de chapa ondulada y los muros son de relleno de tapial.

\footnotetext{
${ }^{8}$ Huerta, Santiago. Las bóvedas de Guastavino en América: libro publicado con ocasión de la exposición: Guastavino Co. (1885-1962) Madrid: Instituto Juan Herrera, 2001.
} 


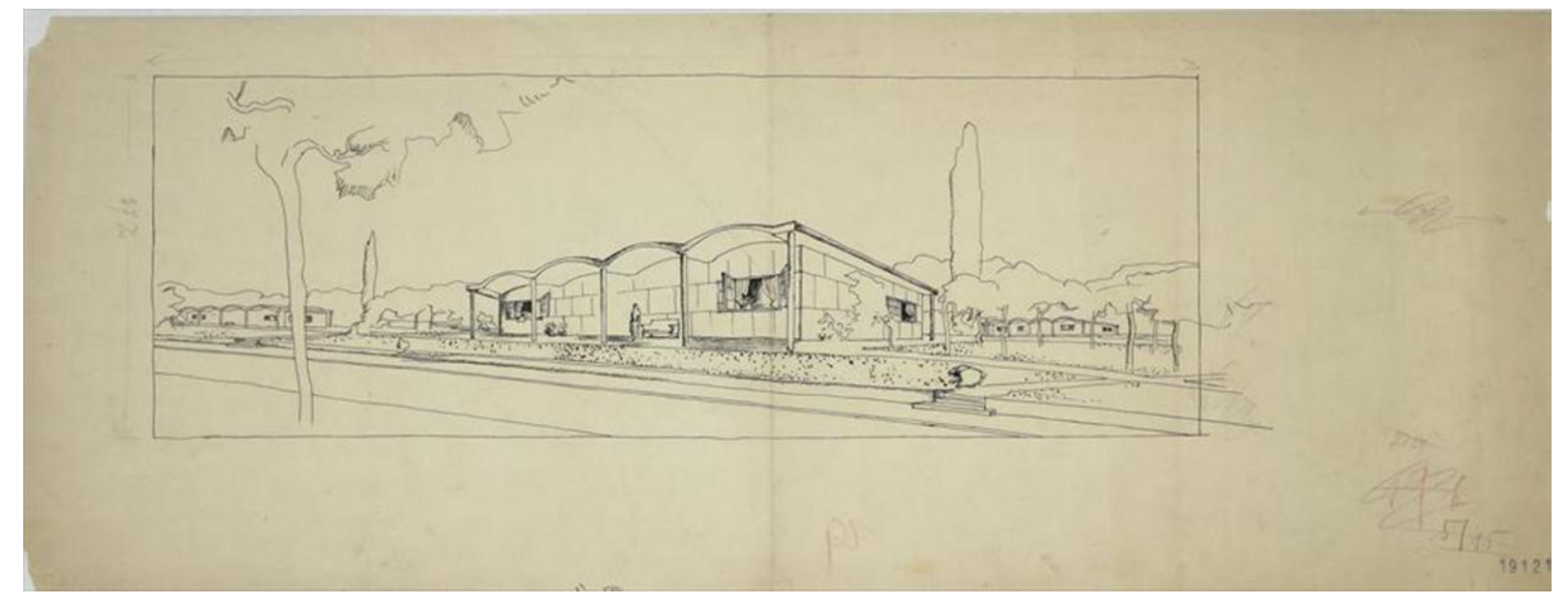

4. Le Corbusier, Dibujo de estudio para las casas Monol. FLC 19121 @ FLC-ADAGP.

Más delante Le Corbusier realizó el proyecto para una pequeña casa de fin de semana en las afueras de París, la casa Henfel (1935), continuando su línea de investigación de este sistema constructivo. En los primeros croquis se puede observar la duda formal en cuanto a la continuidad de la cubierta entre los módulos ${ }^{9}$. En el proyecto preliminar del proyecto de la casa de fin de semana la Celle-Saint-Cloud repite los dibujos de las bóvedas de la escuela parroquial de la Sagrada familia de Gaudí, realizados durante su visita a Barcelona en el Carnet C11. En ambos dibuja respectivamente: a la izquierda las bóvedas catalanas o la casa con tales bóvedas y a la derecha las escuelas de Gaudí o la casa con muros y bóvedas ligeramente onduladas sin ninguna regla geométrica.

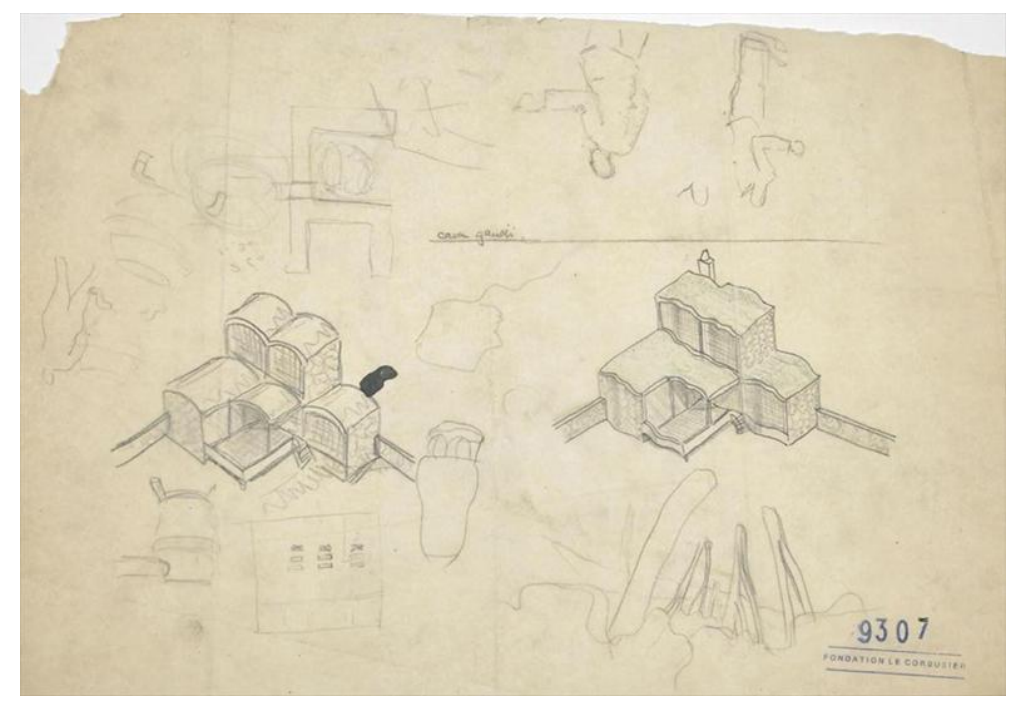

5. Le Corbusier. Croquis preliminares casa de fin de semana, La Celle-saint-Cloud. FLC 09307 C FLC-ADAGP

En este momento de su carrera está todavía presente la búsqueda formal-tipológica y la carga expresiva de un único elemento arquitectónico. La duda entre las dos propuestas, que muestran sus croquis preliminares, responde a la búsqueda de una expresividad conseguida a partir de la repetición en serie o no del sistema abovedado sobre una retícula. Además de esta solución formal, el empleo articulado de diferentes materiales como el ladrillo, vidrio y hormigón aportan al proyecto una cierta autonomía respecto a las vanguardias del

\footnotetext{
${ }^{9}$ Le Corbusier. Le Corbusier \& P.Jeanneret: Ouvre complète 1934-1938. Zurich: d'Architecture Artemis, 1995.
} 
momento. El principal elemento generador del edificio es el elemento abovedado y es la solución que no cambia durante el desarrollo de las diversas hipótesis. Las soluciones características de la propuesta serán la combinación de las paredes de GRC con el muro de piedra y la cubierta abovedada.

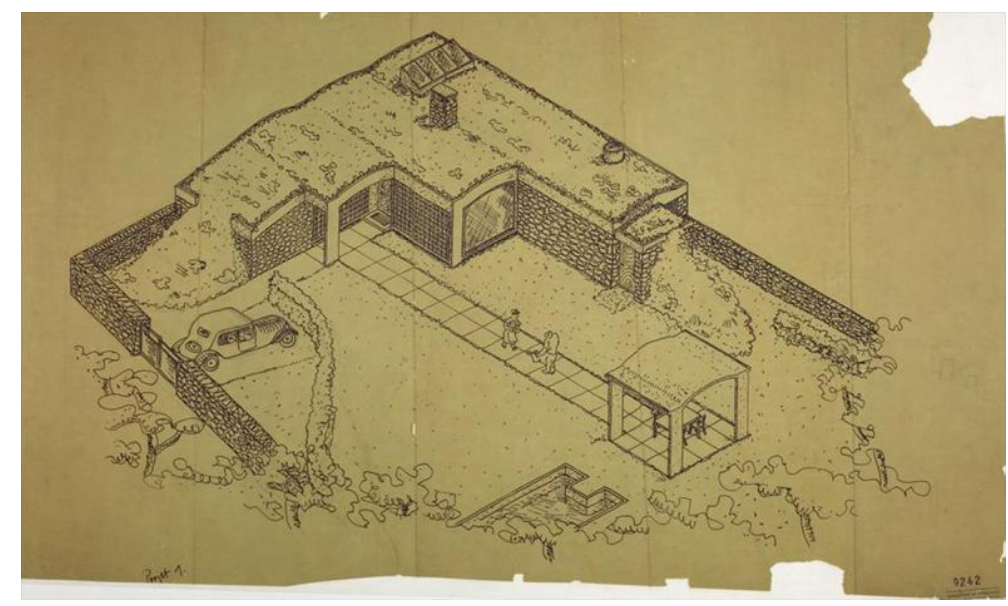

6. Le Corbusier. Croquis preliminares casa de fin de semana, La Celle-saint-Cloud. Se muestra la carga formal del sistema abovedado. FLC 09242 @ FLC-ADAGP

\subsection{Madurez en el uso del sistema abovedado}

Posteriormente realizará uno de sus proyectos abovedados más conocidos, la casa Jaoul en Neuilly-sur-Seine. Ya en la primera sección transversal de este proyecto realizada a mano alzada el 25-7-1951 aparece la bóveda rebajada para cubrir las crujías. Por tanto, los elementos generadores de las casas adosadas son las bóvedas catalanas y la crujía mural, que dan lugar a una tipología espacial y constructiva diferente. La intención espacial de Le Corbusier estaba muy clara en esta casa como podemos observar en varios de sus croquis iniciales con la combinación de bóveda y muro. Las vigas de descarga de las bóvedas se resuelven con vigas metálicas en los muros divisorios, mientras en aquellos de fachada con vigas de hormigón conformado. En la segunda etapa de trabajo en el proyecto, de noviembre a diciembre de 1951, resuelve el perfil de la cubierta con un remate ondulado que cubre toda la sección transversal del edificio generado por la presencia de las bóvedas interiores. Las crujías de ambas casas son distintas, 3,66 y 2,26 metros y la bóveda catalana parte del dintel de las vigas a una altura de 2,26 metros, generando de esta forma un rectángulo áureo ${ }^{10}$.

Los muros longitudinales de ladrillo incorporan jácenas vistas de hormigón que constituyen el apoyo de las bóvedas y cuyos empujes horizontales son absorbidos cada 4,5 metros por tirantes de acero. Al tratamiento exterior de estas vigas de hormigón le proporciona una textura rugosa conferida por el encofrado de tablilla y crea así una alternancia entre el aspecto rugoso del hormigón y el ladrillo caravista del aparejo inglés de los muros de carga ${ }^{11}$.En esta obra tienen una gran presencia la sinceridad constructiva de vigas, bóvedas y muros en contraposición con otras de sus obras.

\footnotetext{
${ }^{10}$ Maniaque Benton, Caroline. Le Corbusier and the Maisons Jaoul. New York: Princeton Archietecture press, 2009.

${ }^{11}$ González Cubero, Josefina. "La arquitectura del suelo. Las casas Jaoul en Neuilly-sur-Seine". En Massilia: Anuario de estudios lecorbusierianos. Barcelona: Fundación Caja de arquitectos, 2003.pp. 162-177.
} 


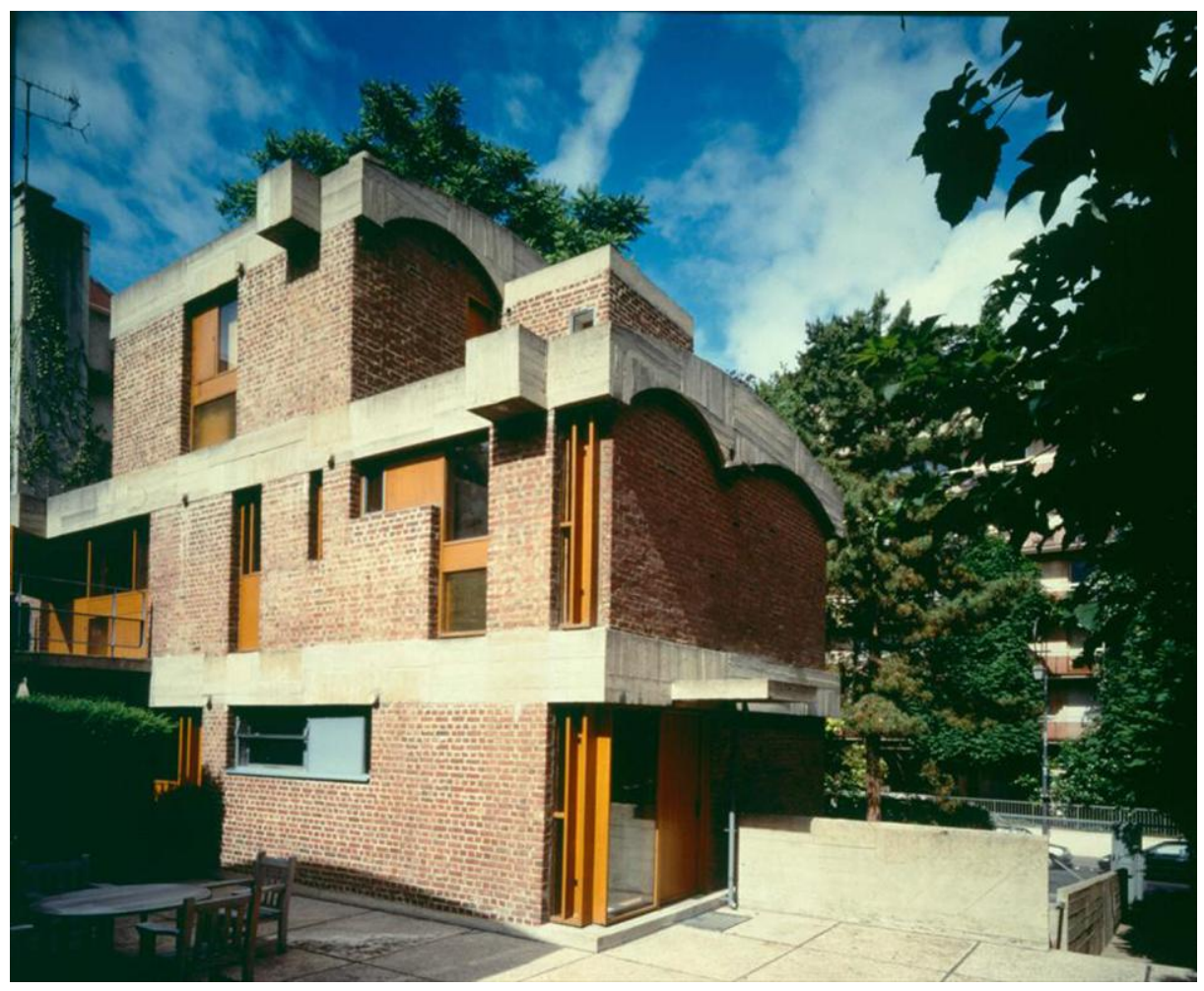

7. Le Corbusier. Vista externa de la casa Jaoul. Alternancia de hormigón y ladrillo. @ FLC-ADAGP

En cuanto a las notas referentes al predimensionamiento estructural de las impostas de las bóvedas de este proyecto se pone de manifiesto una fragmentación entre su intención formal frente a la estructural al utilizar este sistema. Estos cálculos se llevan a cabo mediante la aplicación de fórmulas sencillas como resultado de la teoría elástica de las estructuras de hormigón armado. En tales apuntes no se considera la colaboración de la resistencia del ladrillo. Por tanto el esquema estructural de la bóveda sería el equivalente al de un arco de hormigón con un tirante que contrarresta el empuje horizontal ${ }^{12}$. Este análisis de las notas de Le Corbusier nos confirma el interés del arquitecto por la expresión formal de esta técnica tradicional, dejando a un lado su uso constructivo.

\footnotetext{
${ }^{12}$ Huerta, Santiago. Las bóvedas de Guastavino en América: libro publicado con ocasión de la exposición: Guastavino Co.
} (1885-1962) Madrid: Instituto Juan Herrera, 2001. 


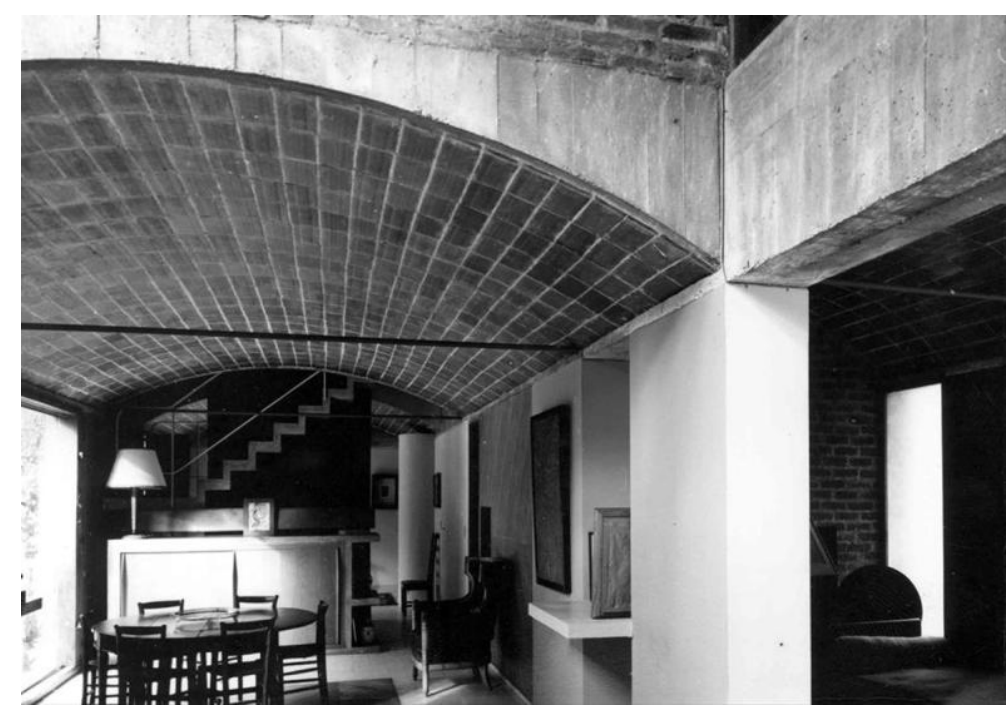

8. Vista interna de la casa Jaoul. Fotógrafo: Lucien Hervé @ FLC-ADAGP

\subsection{Proyectos de bóveda catalana fuera de Europa: Solución ante la carencia de medios técnicos.}

Gracias a que Le Corbusier tuvo la oportunidad de construir en India podrá exportar allí su sistema abovedado. Uno de esos proyectos será la casa Sarabhai (1955) en Gujarat State usando al igual que en las casas Jaoul la bóveda catalana rematada con cubierta ajardinada. La solución tanto tipológica como constructiva de las bóvedas es la misma que la de ésta última casa: dos estratos, uno con ladrillos cuadrados de espesor $2 \mathrm{~cm}$ y otro con bloques perforados de hormigón aligerado de $5 \mathrm{~cm}$, apoyados sobre vigas de hormigón armado ${ }^{13}$ Este sistema constructivo de bóvedas apoyadas en vigas de hormigón armado a vista permite abrir libremente huecos en los muros, dispuestos en paralelo y proporciona un efecto arquitectónico tremendamente vivo.

Asimismo, en el proyecto de las maisons des peons de Chandigarh en 1952 utiliza este procedimiento formal. Esta obra y la casa Jaoul constituyen el inicio y el fin de la incorporación real de las bóvedas catalanas en su obra. Le Corbusier plantea el uso de la construcción tabicada en este proyecto ya que se trata de una técnica rápida, eficaz y económica. Por ello merecía la pena su aprendizaje y empleo en la India, debido al amplio número a realizar y los problemas de escasez de medios técnicos en el lugar. Este planteamiento ya había estado presente en el proyecto para M.Peyrissac en Cherchell (Norte de África, 1942), en el que propone unas bóvedas tabicadas construidas por los indígenas. También en este proyecto está condicionado por el lugar y el momento, pues no existía mano de obra especializada y los materiales eran difíciles de encontrar ${ }^{14}$.

\footnotetext{
${ }^{13}$ Huerta, Santiago. Las bóvedas de Guastavino en América: libro publicado con ocasión de la exposición: Guastavino Co. (1885-1962) Madrid: Instituto Juan Herrera, 2001.

${ }^{14}$ Willy Boesiger. Le Corbusier 1910-1965. Barcelona: Editorial Gustavo Gili S.A., 1994
} 


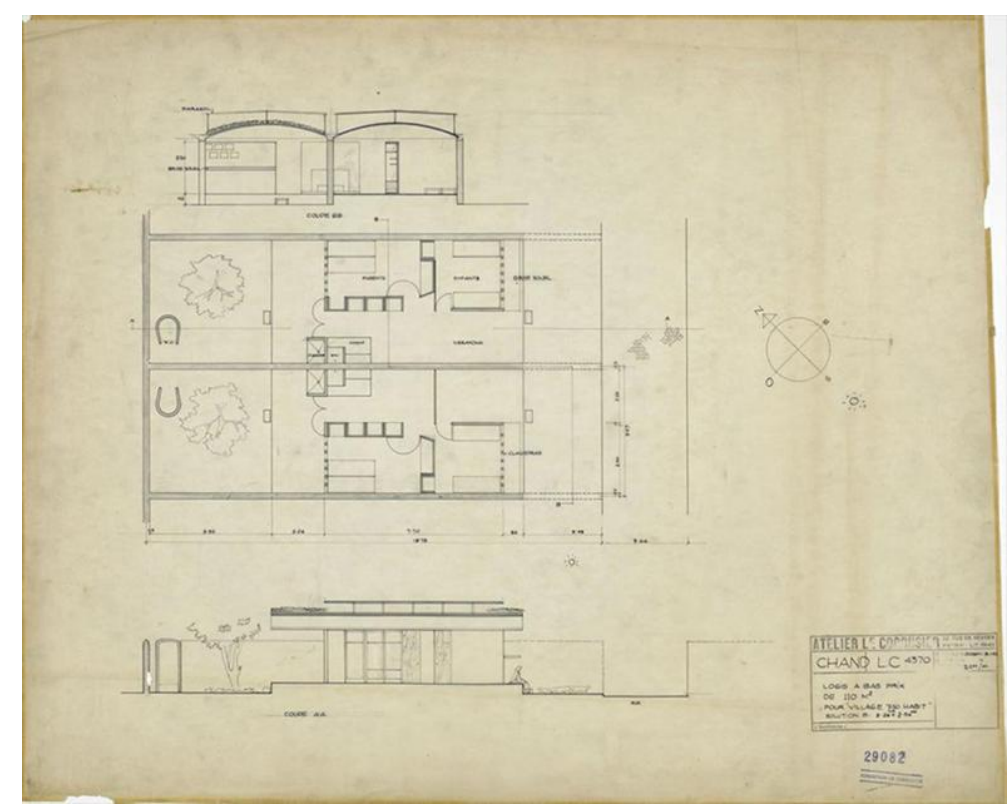

9. Le Corbusier. Planta y secciones de la Maison des Péons, Chandigarh. FLC 29082 @ FLC-ADAGP

\section{Conclusiones}

Le Corbusier a través de todas estas obras y de su búsqueda por entender e interpretar el sistema de la bóveda catalana pretende definir un modelo arquitectónico basado en los sistemas tradicionales que pudiera ser fácilmente adaptable a cualquier espacio, situación o contexto. No se trata simplemente de utilizar una solución constructiva ya definida, sino de reinterpretarla y adaptarla a la realidad y a las facilidades del momento. Los principales puntos de su investigación examinaban un sistema constructivo capaz de abaratar los costes de producción mediante la utilización de bloques de hormigón normalizados pero manteniendo presente la forma de la técnica tradicional.

Se puede observar una evolución en su carrera desde el interés inicial por las técnicas industrializadas hasta la posterior utilización de materiales naturales y técnicas tradicionales. Se trata por tanto de un proceso y no de un cambio en su manera de construir, ya que la búsqueda de la modernidad madurada durante el primer periodo será un legado presente durante toda su carrera. La bóveda catalana es el sistema constructivo que le permite experimentar este cambio y su viaje a Barcelona en 1928, con la visita a la escuela de la Sagrada familia, su fuente de inspiración. Esta construcción está presente en su memoria durante toda su carrera y será un recuerdo formal que recordará en numerosas ocasiones.

\section{Procedencia de imágenes}

Todas las imágenes utilizadas en el artículo proceden de la Fundación Le Corbusier, salvo la segunda imagen que es propiedad de la autora del artículo.

\section{Referencias bibliográficas}

Boesiger, Willy. Le Corbusier 1910-1965. Barcelona: Editorial Gustavo Gili S.A., 1994

Díaz de Tuesta, M.José. Aquel Madrid de Le Corbusier. La Residencia de estudiantes recuerda la estancia de los genios de la arquitectura. Madrid: El País, 2009. 
González Cubero, Josefina. "La arquitectura del suelo. Las casas Jaoul en Neuilly-sur-Seine”. En Massilia: Anuario de estudios lecorbusierianos. Barcelona: Fundación Caja de arquitectos, 2003.pp. 162-177.

Grijalba Bengoetxea, Alberto. Cabrero. La arquitectura de Francisco cabrero. Valladolid: Universidad de Valladolid, 2000.

Huerta, Santiago. Las bóvedas de Guastavino en América: libro publicado con ocasión de la exposición: Guastavino Co. (1885-1962) Madrid: Instituto Juan Herrera, 2001.

Lahuerta, Juan José. Le Corbusier e la Spagna, con la riproduzione dei carnets Barcelone e C10 di Le Corbusier. Milano: Mondadori Electa, 2006.

Le Corbusier. Discurso "Air, son lumière". Pronunciado en Atenas el 3 de agosto de 1933 con motivo del IV CIAM. Atenas, 1933.

Le Corbusier. Le Corbusier \& P.Jeanneret: Ouvre complète 1934-1938. Zurich: d'Architecture Artemis, 1995.

Maniaque Benton, Caroline. Le Corbusier and the Maisons Jaoul. New York: Princeton Archietecture press, 2009.

Sert, Josep Luis. ¿Qué orientación debe darse a la arquitectura contemporánea en Cataluña? En revista del GATEPAC. Barcelona 1934, AC nº16 pp. 43-44. 